\title{
Correlation between Facial Measurements and Occlusal Vertical Dimension: An Anthropometric Study in Two Ethnic Groups of Nepal
}

\author{
Bishal Babu Basnet ${ }^{*}$, Raj Kumar Singh, Prakash Kumar Parajuli, Pragya Shrestha \\ Department of Prosthodontics, B. P. Koirala Institute of Health Sciences, Dharan, Nepal \\ *Corresponding author: bishal_bpkihs@yahoo.com
}

Received September 23, 2014; Revised November 24, 2014; Accepted December 01, 2014

\begin{abstract}
Establishment of proper occlusal vertical dimension is the important yet daunting task for successful prosthodontic therapy for function, esthetics and comfort to the edentulous patients. In the current study the relationship of various distances between facial landmarks to the OVD was tested in two ethnic groups of Nepal, viz. Aryans and Mongoloids. The result of this study can be useful in determining proper OVD in the patients who have lost the OVD. The aim of the study was to find the correlation between facial landmarks and OVD. Materials and methods: The OVD was measured using a Boley gauge from the prominent part of chin and nose. Other facial landmarks were also measured using the calipers in 200 adult volunteers. Results: The Pearson's product moment correlation coefficient was determined. OVD was significantly $(\mathrm{p} \leq 0.05)$ correlated with rima oris to pupil distance $(\mathrm{r}$ $=0.557$ in whole population, $r=0.577$ in Aryans and 0.466 in Mongoloids). Conclusions: The distance between rima oris to pupil distance has higher correlation to OVD than other facial measurements.
\end{abstract}

Keywords: occlusal vertical dimension, rima oris to pupil distance, eye-ear distance, vertical height of ear

Cite This Article: Bishal Babu Basnet, Raj Kumar Singh, Prakash Kumar Parajuli, and Pragya Shrestha, "Correlation between Facial Measurements and Occlusal Vertical Dimension: An Anthropometric Study in Two Ethnic Groups of Nepal.” International Journal of Dental Sciences and Research, vol. 2, no. 6 (2014): 171-174. doi: 10.12691/ijdsr-2-6-13.

\section{Introduction}

Glossary of Prosthodontic Terms [1] defines the occlusal vertical dimension as the distance between two selected points when the occluding members are in contact and rest vertical dimension as the distance between two selected points when mandible is in physiologic rest position. For a successful denture in terms of esthetics and function correct vertical dimension should be determined [2].

In clinical practice, there exists no universal rule for determining correct vertical dimension at occlusion because of wide range of individual variation. [3] Use of pre-extraction records, [4] maximum biting force, [5] electrymyographic method, [6] and cephalometric radiograph [7] are some of the techniques utilized for determining occlusal vertical dimension. Millet et al. [8] recommended using multiple methods, like physiologic rest position, swallowing, phonetic, esthetics and facial measurements. Distance between soft tissue landmarks of face was significantly correlated to occclusal vertical dimension. [9] The facial landmarks can reliably be used to determine occlusal vertical dimension in edentulous patients since they are accessible and relatively unchanged throughout life.
The purpose of this study was to evaluate the correlation between facial measurements and occlusal vertical dimension in two ethnic groups of Nepal.

\section{Materials and Methods}

Two hundred subjects between 19 and 46 years (mean age 25 years) were randomly selected from among the students, staffs, patients and relatives of patients visiting the College of Dental Surgery, B. P. Koirala Institute of Health Sciences. The study was approved by ethical review board of the institute. Each subject was asked to sign the informed consent form prior to commencement of the study. They were divided into two groups according to ethnicity, Aryans and Mongoloids. The inclusion criteria were full set of dentition, straight profile on visual examination, absence of malocclusion, no history of orthodontic and prosthodontic treatment. The exclusion criteria were missing teeth, malocclusion, convex or concave facial profile, history of orthodontic and prosthodontic treatment. Each subject was instructed to relax the lips and close mouth in centric relation. For determining centric relation the bimanual manipulation technique was utilized. [10] The occlusal vertical dimension was measured between most prominent part of chin and nose (Figure 1). Other facial measurements measured were the distance between pupil of eye to corner 
of mouth (rima oris) as shown in Figure 2, distance between outer canthus of one eye to inner canthus of other eye (Figure 3), distance between outer canthus to midpoint of external auditory meatus (Figure 4) and vertical height of ear (Figure 5). These landmarks have been explained as methods to determine occlusal vertical dimension. [11] The data were entered into Microsoft excel and analyzed with statistical package for social science (SPSS) 11.0 version. Independent sample t test was performed to test the difference of means of studied parameters in males and females and in Aryans and Mongoloids. Correlation between these facial measurements and occlusal vertical dimension was studied with Pearson's correlation coefficient (r) at the significance level $\leq 0.05$ and $95 \%$ confidence interval.

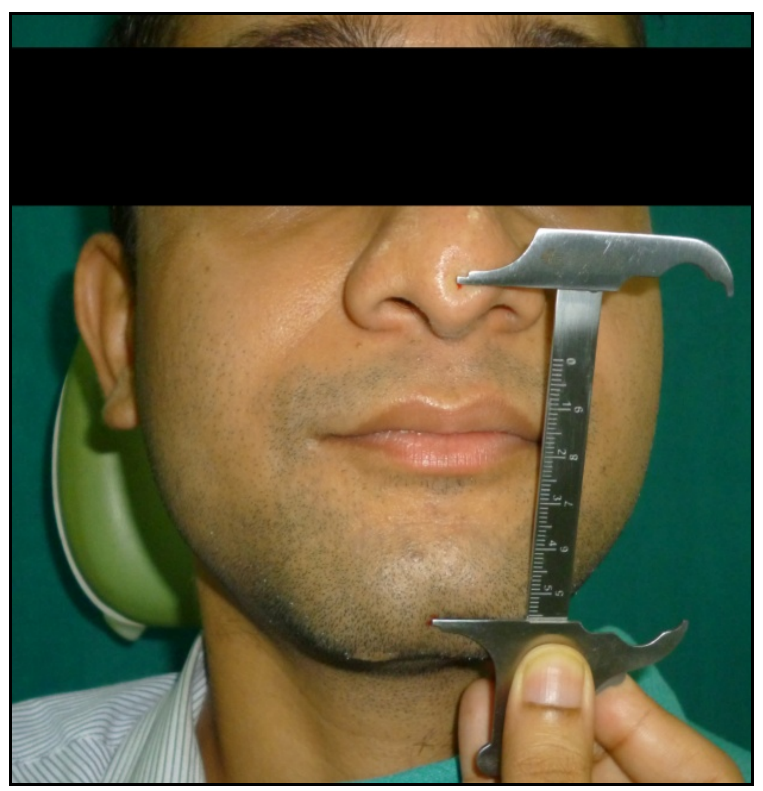

Figure 1. Measurement of OVD by Boley gauge

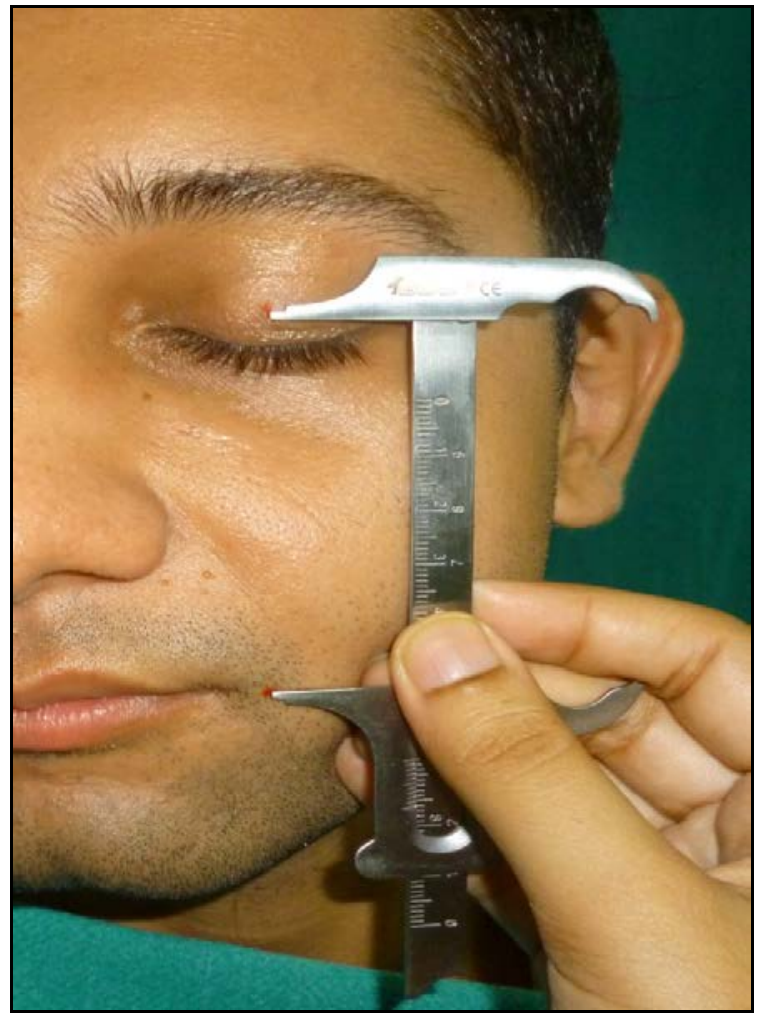

Figure 2. Measurement of distance from rima oris to pupil of eye

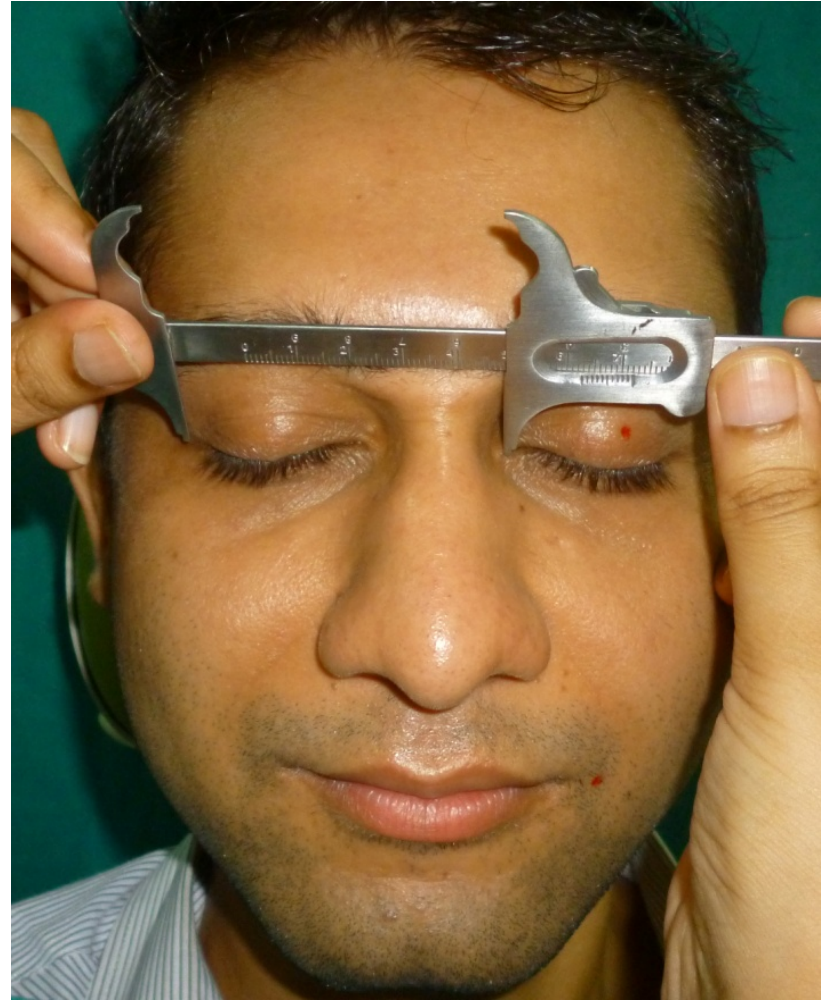

Figure 3. Measurement of distance from outer canthus of one eye to inner canthus of other eye

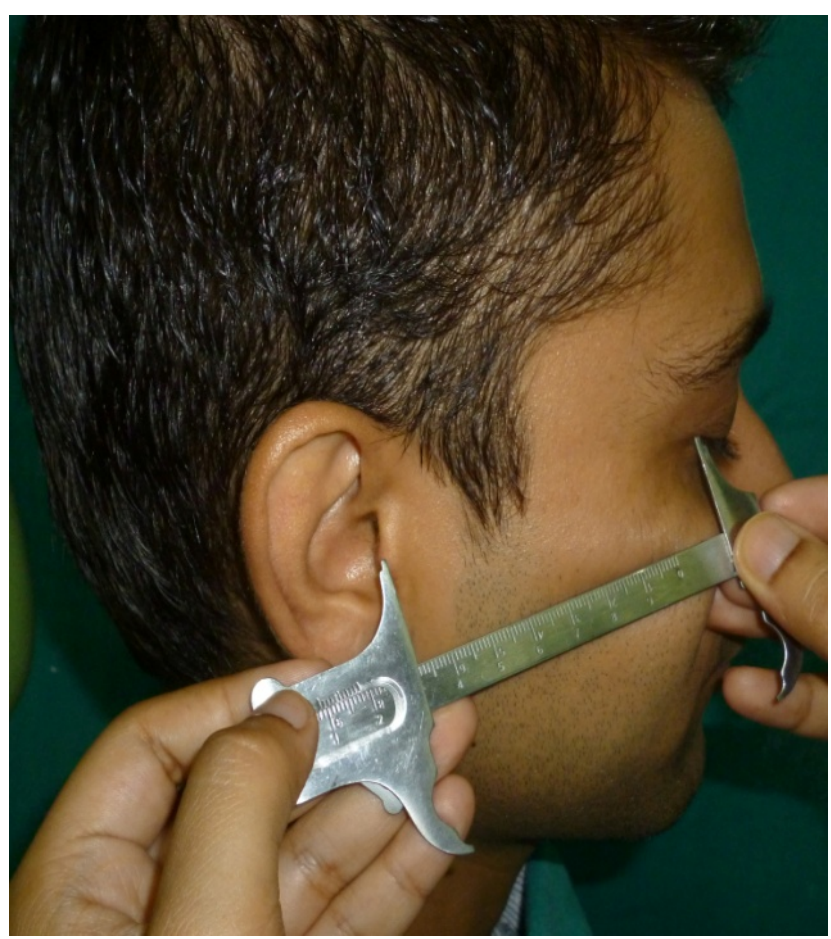

Figure 4. Measurement of eye-ear distance

\section{Results}

The mean occlusal vertical dimension of studied sample was $64.87 \pm 5.21 \mathrm{~mm}$. In Aryans, it was $\mathrm{mm}$ and in Mongoloids $\mathrm{mm}$. The Table 1-Table 4 show the results of this study. It was found that males have significantly longer dimension of OVD. The difference of means of rima oris to pupil distance, vertical height of ear, distance between outer canthus of one eye to inner canthus of other 
eye and eye-ear distance between males and females was not statistically significant. As we compared two ethnicities (Table 3), it was found that OVD and rima oris to pupil distance were significantly longer in Mongoloids whereas eye-ear distance was significantly longer in Aryans than Mongoloids.

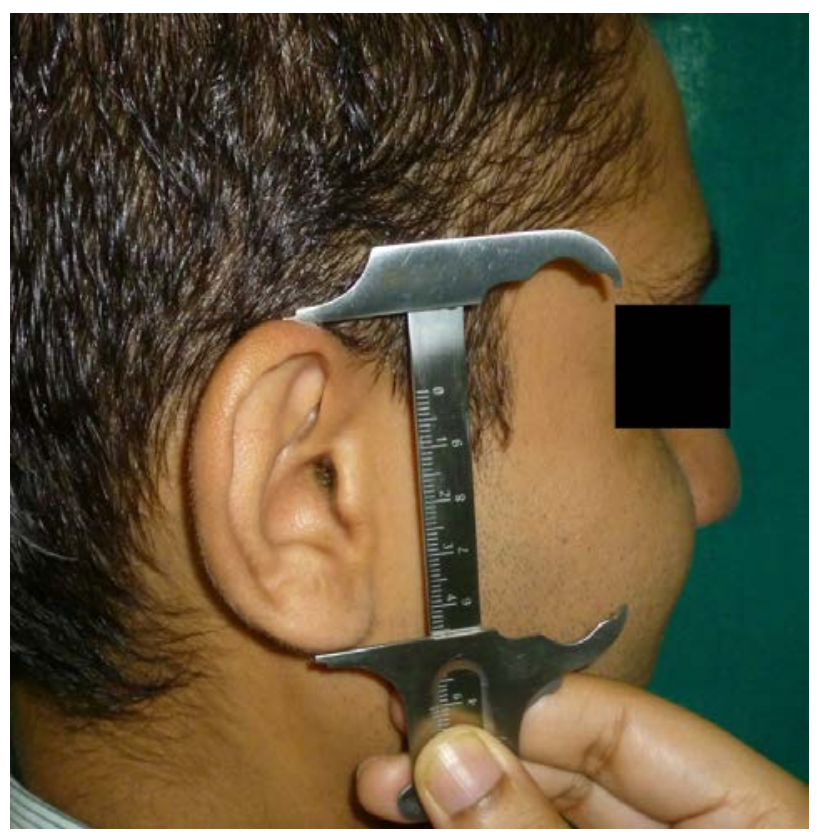

Figure 5. Measurement of vertical height of ear

Table 1. Descriptive statistics of OVD and other facial measurements for total subjects

\begin{tabular}{|c|c|c|c|c|c|}
\hline Character & Number & Minimum & Maximum & Mean & $\begin{array}{c}\text { Std. } \\
\text { deviation }\end{array}$ \\
\hline Age & 200 & 19 & 46 & 25 & 4.78 \\
\hline OVD & 200 & 48 & 77 & 64.87 & 5.21 \\
\hline RO-Pu & 200 & 52.5 & 72 & 64.77 & 4.65 \\
\hline OC-IC & 200 & 55 & 77 & 66.99 & 3.74 \\
\hline E-E & 200 & 53 & 82 & 69.32 & 4.17 \\
\hline EH & 200 & 48.4 & 71 & 60.25 & 3.75 \\
\hline
\end{tabular}

OVD- occlusal vertical dimension, $\mathrm{RO}-\mathrm{Pu}$ - distance between rima oris to pupil of eye, OC-IC - distance between outer canthus of one eye to inner canthus of other eye, E-E - eye ear distance, EH- vertical height of ear.
Table 2. Group statistics of OVD and other measurements comparing gender

\begin{tabular}{|c|c|c|c|c|c|}
\hline Parameters & Gender & $\mathrm{N}$ & Mean \pm S.D. & $\mathrm{p}$ value & Remarks \\
\hline \multirow{2}{*}{ OVD } & Male & 120 & $65.90 \pm 4.31$ & \multirow{2}{*}{0.001} & \multirow{2}{*}{ Sig. } \\
\hline & Female & 80 & $63.35 \pm 6.03$ & & \\
\hline \multirow{2}{*}{$\mathrm{RO}-\mathrm{Pu}$} & Male & 120 & $64.78 \pm 4.43$ & \multirow{2}{*}{0.437} & \multirow{2}{*}{ NS } \\
\hline & Female & 80 & $64.77 \pm 4.98$ & & \\
\hline \multirow{2}{*}{ OC-IC } & Male & 120 & $67.27 \pm 3.40$ & \multirow{2}{*}{0.053} & \multirow{2}{*}{ NS } \\
\hline & Female & 80 & $66.57 \pm 4.19$ & & \\
\hline \multirow{2}{*}{ E-E } & Male & 120 & $70.33 \pm 3.91$ & \multirow{2}{*}{0.967} & \multirow{2}{*}{ NS } \\
\hline & Female & 80 & $67.83 \pm 4.11$ & & \\
\hline \multirow{2}{*}{$\mathrm{EH}$} & Male & 120 & $60.93 \pm 3.75$ & \multirow{2}{*}{0.421} & \multirow{2}{*}{ NS } \\
\hline & Female & 80 & $59.23 \pm 3.55$ & & \\
\hline
\end{tabular}

p-value significant at $\leq 0.05$ level. Sig.- significant, NS- not significant.

Table 3. Group statistics of OVD and other measurements comparing ethnicity

\begin{tabular}{|c|c|c|c|c|c|}
\hline Parameters & Ethnicity & $\mathrm{N}$ & Mean \pm S.D. & $\mathrm{p}$ value & Remarks \\
\hline \multirow{2}{*}{ OVD } & Aryan & 100 & $63.89 \pm 6.29$ & \multirow{2}{*}{$<0.001$} & \multirow{2}{*}{ Sig. } \\
\hline & Mongoloids & 100 & $65.86 \pm 3.61$ & & \\
\hline \multirow{2}{*}{$\mathrm{RO}-\mathrm{Pu}$} & Aryan & 100 & $62.65 \pm 4.65$ & \multirow{2}{*}{0.003} & \multirow{2}{*}{ Sig. } \\
\hline & Mongoloids & 100 & $66.90 \pm 3.56$ & & \\
\hline \multirow{2}{*}{ OC-IC } & Aryan & 100 & $66.42 \pm 3.95$ & \multirow{2}{*}{0.062} & \multirow{2}{*}{ NS } \\
\hline & Mongoloids & 100 & $67.56 \pm 3.45$ & & \\
\hline \multirow{2}{*}{ E-E } & Aryan & 100 & $70.12 \pm 4.81$ & \multirow{2}{*}{$<0.001$} & \multirow{2}{*}{ Sig. } \\
\hline & Mongoloids & 100 & $68.54 \pm 3.24$ & & \\
\hline \multirow{2}{*}{$\mathrm{EH}$} & Aryan & 100 & $60.29 \pm 3.78$ & \multirow{2}{*}{0.200} & \multirow{2}{*}{ NS } \\
\hline & Mongoloids & 100 & $60.21 \pm 3.75$ & & \\
\hline
\end{tabular}

p-value significant at $\leq 0.05$ level. Sig.- significant, NS- not significant.

The correlation between the facial measurements and occlusal vertical dimension was found statistically significant in both ethnicities (Table 4). However, the correlation between rima oris to pupil distance was stronger than the others. It was also noted that correlation between other facial measurements (eye-ear distance, distance between canthi and vertical height of ear) in Mongoloids was relatively weaker. Overall, rima oris to pupil distance was significantly correlated to occlusal vertical dimension (Table 5) with stronger correlation than other facial measurements.

Table 4. Correlation between OVD and other parameters in two ethnic groups

\begin{tabular}{|c|c|c|c|c|c|c|}
\hline & \multicolumn{3}{|c|}{ Aryans } & \multicolumn{3}{|c|}{ Mongoloids } \\
\hline Measurements & Pearson's r & p-value & Significance & Pearson's r & p-value & significance \\
\hline OVD & 1 & & & 1 & & \\
\hline $\mathrm{RO}-\mathrm{Pu}$ & 0.577 & $<0.001$ & Sig. & 0.466 & $<0.001$ & Sig. \\
\hline OC-IC & 0.508 & $<0.001$ & Sig. & 0.307 & 0.002 & Sig. \\
\hline E-E & 0.498 & $<0.001$ & Sig. & 0.320 & 0.001 & Sig. \\
\hline $\mathrm{EH}$ & 0.471 & $<0.001$ & Sig. & 0.278 & 0.005 & Sig. \\
\hline
\end{tabular}

p-value significant at $\leq 0.05$ level. Sig.- significant, NS- not significant

Table 5. Correlation between OVD and other parameters in studied sample $(\mathrm{N}=\mathbf{2 0 0})$

\begin{tabular}{|c|c|c|c|}
\hline Measurements & Pearson's $\mathrm{r}$ & $\mathrm{p}$-value & Significance \\
\hline OVD & 1 & & \\
\hline RO-Pu & 0.557 & $<0.001$ & Sig. \\
\hline OC-IC & 0.499 & $<0.001$ & Sig. \\
\hline E-E & 0.395 & $<0.001$ & Sig. \\
\hline EH & 0.378 & $<0.001$ & Sig. \\
\hline
\end{tabular}

p-value significant at $\leq 0.05$ level. Sig.- significant, NS- not significant.

\section{Discussion}

The loss of teeth results in poor appearance of lower third of face. The restoration of correct vertical dimension in those who have lost it should be in harmony with the upper part of face. Prosthodontists have long been seeking for universally accepted method of determining the OVD. There were methods like use of anterior teeth measurements 
[12], closest speaking space [13], swallowing method [14], patient's neuromuscular perception [15], cephalometric radiographs [16], intra-oral and extra-oral anatomic landmarks [17] and measurement of fingers. [18] All of these methods possess some kinds of disadvantages. The present study gave some idea about facial measurement and their use in determining occlusal vertical dimension.

In present study the occlusal vertical dimension was found $65.90 \pm 4.31 \mathrm{~mm}$ in male and $63.35 \pm 6.03 \mathrm{~mm}$ in female. These were found to be longer than the findigs of Ladda et al. [16] $(61.4 \pm 4.2 \mathrm{~mm}$ in male and $56.7 \pm 3.0 \mathrm{~mm}$ in female) and Kulakarni and Kohli [17] (54 to $59 \mathrm{~mm}$ in female and 62 to $65 \mathrm{~mm}$ in male). The distance between ANS and Me from cephalometric radiograph in Serbian population, was $67.87 \pm 5.67 \mathrm{~mm}$ in male and $61.51 \pm 5.06$ $\mathrm{mm}$ in female. [7] Similar measurements were observed in Iraqi adult population reported by Al-Hamadany [20] where occlusal vertical dimension in 75 students was $66.74 \pm 6.468 \mathrm{~mm}$. The OVD in males was $68.25 \pm 6.134$ $\mathrm{mm}$ and in females, it was $63.99 \pm 6.254 \mathrm{~mm}$. These values are consistent to that of current study.

The correlation was statistically significant and positive with rima oris to pupil of eye $(r=0.557)$, followed by distance between outer canthus of one eye to inner canthus of other eye $(r=0.449)$ and eye-ear distance $(r=0.395)$ and vertical height of ear $(r=0.378)$. This is in contrast with the study done by Delic et al. [21] The correlation of eye-ear distance $(r=0.8676)$ was stronger than pupil to rima oris distance $(\mathrm{r}=0.4357)$ in their study. Rima-oris to pupil distance was longer than lower facial height by $3 \mathrm{~cm}$ in a study done in Phillipinos by Tina-Olaivar et al [22].

The limitations of the study were only two ethnic groups were taken into consideration and the findings cannot be extrapolated to other races. Also, the sample size was very small to conclude the findings. The occlusal vertical dimension is not constant and dynamic. Therefore the anthropometric measurement in dentulous subjects can be an adjunct but not accurate for utilizing in edentulous patients. There need to be further investigations to endorse or refute the findings of present study in this part of world as most of studies are found pertaining to developed countries.

\section{Conclusions}

Anthropometric measurements of facial landmarks were recorded for 200 subjects (100 Aryans and 100 Mongoloids) and correlation of facial measurements to occlusal vertical dimension was tested. Within the limitations of this study, we can conclude that the facial measurements are significantly correlated to the occlusal vertical dimension. Findings of this study will be helpful guide in determination of occlusal vertical dimension.

\section{Conflict of Intrest}

None of the authors have any conflict of interest.

\section{References}

[1] The glossary of prosthodontics terms. J Prosthet Dent. 2005 Jul; 94(1).

[2] Heartwell CM, Rahn AO. Syllabus of complete dentures. $2^{\text {nd }}$ ed. Philadelphia: Lea \& Febiger, 1974; 194-6.

[3] Hurst WW. Vertical dimension and its correlation with lip length and interocclusal distance. J Am Dent Assoc 1962; 64: 496-504.

[4] Bissau M. Pre-extraction records for complete denture fabrication: a literature review. J Prosthet Dent. 2004 Jan; 91(1): 55-8.

[5] Boos RH. Intermaxillary relation established by biting power. $J$ Am Dent Assoc 1940; 27: 1192-9.

[6] Miljcovic Z, Zeljkovic M, Anojcic M. Comparison of physiologic methods of determination of occlusal vertical dimension in edentulous persons. Vojnosanit Pregl. 2001 Jul-Aug; 58(4): 381-7.

[7] Strajnic L, Stanisic-Sinobad D, Markovic D, Stojanovic L. Cephalometric indicators of the vertical dimension of occlusion. Coll Antropol. 2008; 32(2): 535-41.

[8] Millet C, Leterme A, Jeannin C, Jaudoin P. Vertical dimension in the treatment of edentulous patient. Rev Stomatol Chir Maxillofac. 2010 Nov-Dec.; 111(5-6): 315-30.

[9] Al-Hamdany AK, Kassab NH. Correlation of vertical dimensions of soft tissue facial profiles. Al-Rafidain Dent J. 2010; 10(2): 24353.

[10] Dawson Peter E. Functional Occlusion from TMJ to Smile Design: Mosby; 2007.

[11] Misch CE. Contemporary implant dentistry. 3nd ed. St. Louis: Mosby; 2008.

[12] Ekfeldt A, Karlsson S. Influence of lower lip support on recording of vertical dimension in edentulous patients. J Oral Rehabil. 1992; 19: 313-7.

[13] Silverman MM. The speaking method in measuring vertical dimension. J Prosthet Dent. 1953 Mar; 3(2): 193-9.

[14] Shanahan TEJ. Physiologic vertical dimension and centric relation, J Prosthet Dent. 1956; 6: 741-7.

[15] Lytle RB. Vertical relation of occlusion by the patient's neuromuscular perception. J Prosthet Dent. 1964 Jan-Feb; 14(1): 12-21.

[16] Basler FL, Douglas JR, Moulton RS. Cephalometric analysis of the vertical dimension of occlusion. J Prosthet Dent. 1961; 11: 831-5.

[17] Fayz F, Eslami A. Determination of occlusal vertical dimension: a literature review. J Prosthet Dent. 1988 Mar; 59(3): 321-3.

[18] Ladda R, Bhandari AJ, Kasat VO, Angadi GS. A new technique to determine vertical dimension of occlusion from anthropometric measurements of finger. Indian J Dent Res. 2013; 24: 316-20.

[19] Kulkarni N, Kohli M. Estimation and correlation of individual facial height and total body height. J Int Oral Health. 2011 Apr; 3(2): 37-42.

[20] Al-Hamdany AK, Kassab NH. Correlation of vertical dimensions of soft tissue facial profiles. Al-Rafidain Dent J. 2010; 10(2): 24353.

[21] Delic Z, Simunovic-Soskic M, Perinic-Grzic R, Vukovojac S, Rajic Z, Kuna T. Evaluation of craniometric methods for determination of vertical dimension of occlusion. Coll Antropol. 2000; 1(suppl. 24): 31-5.

[22] Tina-Olaivar EO, Olaivar OK. A comparative study of the upper and lower vertical facial measurements of the Filipinos as it is used in the Willis method for determining the vertical dimension of occlusion. J Philipp Dent Assoc. 1998 Jun-Aug;50(1): 44-8. 